\title{
Systems for the management of respiratory disease in primary care - an international series: Australia
}

\author{
*Nicholas Glasgow ${ }^{a}$ \\ a The Australian National University - Australian National University Medical School, Australia
}

Received 12th December 2007; revised version received 16th January 2008; accepted 24th January 2008

\begin{abstract}
Introduction: Australia has a complex health system with policy and funding responsibilities divided across federal and state/territory boundaries and service provision split between public and private providers. General practice is largely funded through the federal government. Other primary health care services are provided by state/territory public entities and private allied health practitioners. Indigenous health services are specifically funded by the federal government through a series of Aboriginal Community Controlled Organisations.

National policy and models: The dominant primary health care model is federally-funded private "small business" general practices. M edicare reimbursement items have incrementally changed over the last decade to include increasing support for chronic disease care with both generic and disease specific items as incentives. Asthma has received a large amount of national policy attention. Other respiratory diseases have not had similar policy emphasis.

Epidemiology: Australia has a high prevalence of asthma. Respiratory-related encounters in general practice, including acute and chronic respiratory illness and influenza immunisations, account for $20.6 \%$ of general practice activity. Lung cancer is a rare disease in general practice. Tuberculosis is uncommon and most often found in people born outside of Australia. Aboriginal and Torres Strait Islanders have higher rates of asthma, smoking and tuberculosis.

Access to care: Access to care is positively influenced by substantial public funding underpinning both the private and public sectors through Medicare. Access to general practice care is negatively influenced by workforce shortages, the ongoing demands of acute care, and the incremental way in which system redesign is occurring in general practice.

Facilities available: M ost general practice operates from privately-owned rooms. The Australian Government requires general practice facilities to be accredited against certain standards in order for the practice to receive income from a number of government programs. These standards require GPs to have ready access to spirometry, but do not require every practice to have a spirometer.

Future: The initial assessment and management of acute respiratory illnesses currently seen in primary health care settings will continue, but for this to occur the sector may have to adapt traditional workforce roles because of workforce shortages. In the longer term, climate change and migration patterns may result in changes in the epidemiology of regions and populations. The health system will continue to reform incrementally in order to deliver improved chronic disease care, including care of people with asthma and COPD. The incoming Labor Government's National Primary Health Care Strategy provides the high level policy opportunity to drive reform.

Conclusions: Australia's complex primary health care system is incrementally changing from one of exclusive acute- and episodic-care orientation in both the public and private sectors to a system that delivers effective anticipatory chronic disease care as well. From a national policy perspective, asthma has received most attention. COPD and possibly other respiratory diseases may now receive focus.

(c) 2008 General Practice Airways Group. All rights reserved.

N Glasgow. Prim Care Resp J 2008; 17(1): 19-25.

doi:10.3132/pcrj.2008.00015
\end{abstract}

Keyw ords Australia, respiratory disease, management, primary care, systems, funding

\section{Contents}

Introduction

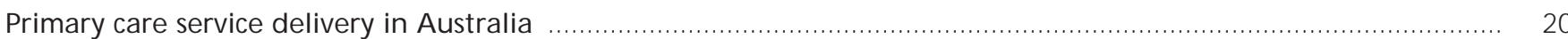

National policy and health service model for providing respiratory care in primary care settings

\footnotetext{
* Corresponding author: Professor Nicholas Glasgow, The Australian National University - Australian National University Medical School, Fenner Building Acton Australian Capital, Territory 0200, Australia. E-mail: nicholas.glasgow @anu.edu.au
} 
Epidemiology

Access to Care

Facilities.

Future developments

Conclusion

References

\section{See editorial by Beilby, Williams and Levy on page 5}

\section{Introduction}

This paper on the current provision of primary care services for patients with respiratory disease in Australia, is the first in a planned series of international reviews. In keeping with the aims and objectives of the Primary Care Respiratory Journal, the editors commissioned this series of papers to enable clinicians and health service managers to compare and learn from different systems of primary care management for patients with respiratory disease around the world. Each of the papers in the series will follow a similar format, and will include information on national policy and models, epidemiology, access to care, facilities available, and future developments. By summarising and comparing how different countries provide primary care for patients with respiratory disease we hope to stimulate debate and inform the future development of policies aimed at improving the care worldwide for people with respiratory disease.

\section{Primary care service delivery in Australia}

The health system in Australia is "a mixture of public and private sector health service providers and a range of funding and regulatory mechanisms." ${ }^{1}$ It is a complex system with policy direction and public funding responsibilities distributed across federal and state/territory jurisdictions. Primary medical care services are predominantly provided within general practice, defined by the Royal Australian College of General Practitioners (RACGP) as "the provision of primary continuing comprehensive whole patient medical care to individuals, families and their communities". 2 These practices usually operate as private small businesses owned and staffed by vocationally-trained medical graduates who have specialised in general practice, supported by combinations of nursing, reception and management personnel; they play a key " gatekeeping" role in terms of access to Australian Governmentfunded diagnostic, pharmaceutical and treatment services. The Australian Government intends access to general practice services to be universal for Australian citizens. The majority of general practice income is derived from fee-for-service payments. General practice activity is supported through the Medicare program. ${ }^{3}$ This program includes the Medicare Benefits Schedule (MBS) that lists the fees the Australian
Government will pay for various services, the Pharmaceutical Benefits Scheme (PBS) that subsidises the costs of listed medications, and it provides free public hospital access. ${ }^{4}$

About $85 \%$ of Australia's population ( 20.3 million) visit a general practitioner (GP) once a year and in 2005 GPs provided more than 90 million consultations - between four and five consultations for each Australian. Referrals, usually to specialists, occurred as a consequence of $11 \%$ of these consultations. $^{5}$

In addition to general practice, the National Aboriginal Community Controlled Health Organisation (NACCHO) is the peak organisation for Aboriginal Community Controlled Health Services that provides comprehensive primary health care services to indigenous Australians through a network of more than 130 Aboriginal M edical Services (AMS). These are "primary health care services initiated and operated by the local Aboriginal community to deliver holistic, comprehensive, and culturally-appropriate health care to the community which controls it (through a locally-elected Board of Management)." ${ }^{6}$

State- or territory-funded community health services contribute to the delivery of primary care through the provision of some community-based services including community nursing and allied health.

Australia's general practice workforce is under pressure. The Australian Medical Workforce Advisory Committee (AMWAC) report "The General Practice Workforce in Australia: supply and requirements to $2013^{\prime \prime} 7$ states that in 2002 the national shortage of GPs was in the range of 800 to 1300 GPs and estimates that between 2007 and 2013 there will be an annual shortage of entrants into the general practice workforce of about 400 to 500 Australian-trained and overseas-trained doctors. Contributing to the GP workforce pressure is emerging data suggesting that younger GPs are not willing to take on the responsibilities of owning a practice, and prefer to work less than full-time in delivering general practice services. There is also a significant shortage of nurses which is projected to worsen over the next decade as many in the current nursing cohort reach retirement age.

The Australian Government has enacted a number of policies to address these shortages, with the net result being an expansion of the number of medical graduates by more than 60 percent over the next six years, and the provision of more places for general practice specialist training. 
Satisfactory completion of this training is mandatory for a medical practitioner to be recognised as a GP and to have consultations eligible for Medicare support. GPs are required to complete triennial cycles of continuing education to maintain professional standards, and can lose their status as GPs if they do not do this.

\section{National policy and health service model for providing respiratory care in primary care settings}

The Australian general practice service model is designed to address the identified health needs of a person presenting to the GP at a particular point in time. Historically, the model has focused on the delivery of reactive acute and episodic health care. The policy framework of Medicare has reflected this focus, emphasising fee-for-service payments for general practice activity. Over the last decade, this policy framework has been incrementally changed with the incorporation within the Medical Benefits Schedule of items specifically aimed at enhancing chronic disease care by making this care more structured and increasing its co-ordination. These items emphasise proactive and anticipatory care, increase the range of services able to be delivered by nurses working in general practice, and drive more multidisciplinary care.

The items include some generic items which can be used for the management of any chronic disease, including asthma, COPD or other less common chronic respiratory disease. The "General Practice Management Plan" (GPMP) item and the "GPMP Review" item are designed to encourage GPs to write a specific care plan with the patient. The "Team Care Arrangement" (TCA) supports GPs in recruiting multidisciplinary care from other health professionals to bear on a particular case. There are also items that support health assessments for older Australians over the age of 75 years and health assessments for Aboriginal and Torres Strait Islanders over the age of 55 years.

Some items are aimed at particular chronic diseases, including asthma, but not any other respiratory disease. The "Asthma Cycle of $\mathrm{Care}^{8}{ }^{8}$ provides incentives to GPs to implement best practice care for people with moderate to severe asthma. It involves at least two visits to a GP over a period of 12 months and includes:

- diagnosis and assessment of asthma severity and level of control

- development of a written asthma action plan

- provision of information and patient self-management education

- review of asthma management and the written asthma action plan

Alongside these incremental changes to Medicare policy are a number of national policy initiatives that specifically address asthma. In 1999, the Australian Health Ministers Advisory Council (AHMAC) established asthma as a national health priority. Since 2006, national strategic direction for asthma-related services has been provided by the National Asthma Strategy 2006-2008. ${ }^{9}$ The strategy is endorsed by AHMAC and is related to the overarching 2005 National Chronic Disease Strategy (NCDS) and the National Service Improvement Framework for asthma. ${ }^{10}$ Other respiratory diseases are not the focus of similar national policy initiatives.

The Australian Government's "Asthma Management Program" was initially funded in 2001 with an allocation of $\$ 48.4$ million up to $2004 / 05$. This funding was extended with an additional $\$ 27.1$ million dollars continuing through until 2009. In addition to supporting the Asthma Cycle of Care (and its precursor, the Asthma $3+$ Visit Plan) the funding supports a number of initiatives including:

- The Australian System for Monitoring Asthma - to support national surveillance and monitoring of asthma

- An Asthma Community Support and Grants Program - providing consumer information and referral to primary care, and a program of research grants to identify effective approaches to asthma management in highneed communities

- The Asthma Friendly Schools Program - providing training, systems and resources for effective asthma management by school communities with the aim of improving the quality of life, health outcomes and well being for school children with asthma

- Asthma awareness raising - a national multi-year campaign to raise awareness of the symptoms and seriousness of asthma and to encourage people with asthma to see their GP with the aim of receiving a written asthma action plan

- A range of professional education activities providing best-practice asthma management education nationally to GPs and allied health professionals through a range of mediums

Although chronic obstructive pulmonary disease (COPD) has not been the focus of specific national policy initiatives, the Australian Lung Foundation (ALF) has developed and actively promoted evidence-based guidelines aimed at general practice for this condition. ${ }^{11}$ The COPD- $X$ guidelines are regularly updated, and are readily available on the ALF website along with GP-orientated resources for lung cancer and respiratory infectious diseases.

\section{Epidemiology}

Australia has one of the highest prevalences of asthma in the world, with one in six children and one in nine adults having the condition. ${ }^{12}$

Table 1 summarises available respiratory illness-related 
primary care data. Diseases of the respiratory tract account for 20.6 per 100 encounters in Australian general practice. Three of every 100 encounters involve the management of asthma or COPD, and primary prevention of influenza occurs in 1.8 of every 100 encounters.

Aboriginal and Torres Strait Islander people have higher rates of asthma and tobacco smoking, and higher rates of mortality across most conditions.

Each year in Australia approximately 1000 people have a new diagnosis of tuberculosis. In 2004, $82.3 \%$ of these cases occurred in overseas-born people. In Australian-born people, incidence rates are greater in indigenous (8.1 - 15.3 per $100,000)$ than non-indigenous $(0.9$ - 1.2 per 100,000$)$ populations. ${ }^{13}$

\section{Access to care}

Australia's health system places a high value on citizens being able to make choices about their health care. This includes choice with regard to selecting their GP and choice with regard to being treated in the public or private system. Public funds support this value on choice both through the Medicare structures and the availability of a publicly-funded $30 \%$ rebate on private health insurance.

As outlined above, Australia has a well established, largely private general practice sector. GPs increasingly are supported by practice nurses in the delivery of care. M ost care continues to be of a reactive type with patients presenting to a GP to have concerns addressed. The GP may use other members of the general practice team to assist in providing the response

Table 1. Respiratory illness-related primary care data.

\begin{tabular}{|c|c|c|c|c|}
\hline & $\begin{array}{l}\text { Rate per } 100 \text { general } \\
\text { practice encounters }{ }^{5}\end{array}$ & $\begin{array}{c}\text { Population } \\
\text { prevalence estimates }\end{array}$ & $\begin{array}{l}\text { Incidence } \\
\text { estimates }\end{array}$ & $\begin{array}{l}\text { Approximate } \\
\text { deaths per year }\end{array}$ \\
\hline $\begin{array}{l}\text { Acute respiratory infections } \\
\text { Acute bronchitis/bronchiolitis }\end{array}$ & 2.5 & & & \\
\hline Acute otitis media & 1.2 & & & \\
\hline Community acquired pneumonia & 0.01 & & aroulo & \\
\hline Influenza & 0.7 & A & & (Estimate) $1000^{13}$ \\
\hline Sinusitis & 1.3 & Dractiou & & \\
\hline Tonsillitis & 1.1000 & apror & & \\
\hline Upper respiratory tract infection & 6.20100 & & & \\
\hline $\begin{array}{l}\text { Chronic respiratory diseases } \\
\text { Asthma }\end{array}$ & 2.3 & $12 \% *$ & & \\
\hline Chronic otitis media & Not available & $1.04 \%+$ & & \\
\hline COPD & 0.7 & $4 \% *$ & & \\
\hline Cystic fibrosis & Not available & $\begin{array}{c}\text { About } 3000 \\
\text { cases in Australia\# }\end{array}$ & & \\
\hline Lung cancer\# & Less than 0.01 & & $\begin{array}{c}\text { Females } \\
\text { About } 3000 \\
\text { cases per year } \\
\text { Males } \\
\text { About } 6000 \\
\text { cases per year }\end{array}$ & $\begin{array}{c}\text { Females } \\
(2000) 2291 \\
\text { Males } \\
(2000) 4587\end{array}$ \\
\hline $\begin{array}{l}\text { Prevention and risk factors } \\
\text { Immunisation (Respiratory) }\end{array}$ & 1.8 & & & \\
\hline Tobacco smoking (All ages 18+) & & $\begin{array}{c}\text { Males } 24.2 \% \\
\text { Females } 18.4 \% *\end{array}$ & & \\
\hline
\end{tabular}

General practice data taken from Britt H, Miller GC, et al 2007. General practice activity in Australia 2005-06. General practice series no. 19. AlHW cat. no. GEP 19. Canberra: Australian Institute of Health and Welfare. http://www.aihw.gov.au/publications/gep/gpaa05-06/gpaa05-06.pdf

* Australian Institute of Health and Welfare. Chronic diseases and associated risk factors in Australia, 2006. Report. Canberra: AlHW, 2006. AlHW publication PHE 81. Available from http://www.aihw.gov.au/publications/phe/cdarfa06/cdarfa06.pdf

+ National Health Survey: Summary of Results 2004-05. Australian Bureau of Statistics http://www.abs.gov.au/AUSSTATS/abs@.nsf/DetailsPage/4364. 02004-05? OpenDocument

\# Case Statement Lung Cancer Update for 2006. The Australian Lung Foundation http://www.lungnet.com.au/download_pdf/ CaseStatement2006updatefinal.pdf 


\section{Case study}

A 50-year old male presents to his GP with a history of productive cough and increasing breathlessness over the last three months. He made the appointment four days earlier. He smokes 20 cigarettes each day and has done so since the age of 18 . There are no other symptoms of note, and the patient expresses concern that his smoking habit might be catching up with him. The GP undertakes a clinical assessment. This reveals no further information. She decides that further investigation is necessary. She arranges for spirometry to be undertaken by her practice nurse. This is booked to take place three days later. She arranges for blood tests to be undertaken by the private pathology provider at no cost to the patient because the provider is reimbursed directly through Medicare. She also refers the patient for a chest Xray at the nearby private radiologist. Although $M$ edicare also reimburses part of the associated fee for this service, the patient has to pay out-of-pocket expenses of $\$ 30.00$. Both of these investigations take place the following day. The GP arranges to review the patient in a week's time when all results are too hand. She directly bills M edicare for a "Level $C^{\prime \prime}$ consultation (AUD\$62.30) because of the time involved ( $>20$ mins but $<40$ mins) and complexity of the case and the patient does not pay her any cash for the service.

She receives an urgent call from the radiologist the next day. There is a suspicious hilar mass evident on the chest $X$ ray. She fits the patient in to her fully-booked day and discusses the result. She discusses whether he would like to see a private specialist or go to the public hospital. He decides to use the public system. She rings the respiratory physician at the local public hospital and discusses the case with him. An urgent appointment is made for the following day. She provides the patient with a referral letter and the chest $X$ ray. She directly bills Medicare for a "Level B" consultation (AUD\$32.80) The patient does not pay for services in the public hospital.

(e.g. the practice nurse may give the influenza immunisation although the GP has to write the prescription for it). The GP may also refer patients for investigation and ongoing management. With the current workforce shortages in general practice and the historical orientation to reactive care, many GPs find their time fully-booked up to two weeks ahead. This makes same day access problematical, with the solution usually being to fit in urgent cases and run late as a consequence. Some practices are making use of the newer Medicare items to reorientate their practice systems to provide anticipatory and preventive care as well as investigations like spirometry through their practice nurses.
The case study opposite provides an example of how different parts of the health system might engage with a particular kind of respiratory complaint and illustrates the interaction between the public and private systems and between general practice and other services. It also illustrates possible out-of-pocket costs involved.

The case study also illustrates how the system best supports acute or episodic care. Access to care for this new and serious condition was quick and effective. Implications for care are not the dismantling of this effective and efficient aspect of the system, but rather the addition of drivers within the system to enhance the delivery of chronic care.

\section{Facilities}

The proportion of solo practitioners in Australian general practice is diminishing, with increasingly large numbers of GPs choosing to work in group practices. In larger urban settings, rooms are purchased or leased as part of the private business operation. In areas of particular need - including rural and remote Australia and some outer metropolitan settings - public health facilities or funds may be provided to the private general practice.

Most general practices are computerised, and regularly use the appointment, billing, and prescribing functions of the various general practice software packages. Increasingly GPs are using clinical information systems within these packages to support chronic disease management. A third of GPs in a recent survey kept all patient information in electronic format. ${ }^{14}$ The software packages often have inbuilt templates that can be used for clinical purposes such as the production of a written asthma action plan. They also include up-to-date information on registered indications for medications and the Pharmaceutical Benefit Schedule subsidies that apply.

To participate in a number of Australian Government programs aimed at incentivising particular general practice activity, general practices must be accredited against standards. These include standards relating to the facilities provided. Current standards for Australian general practice require a practice to have "timely access" to a spirometer. ${ }^{15}$ Within the educational components of the Asthma $M$ anagement Program, there has been considerable emphasis on the importance of spirometry for general practice populations, and training in the use of spirometry and interpretation of the results. The Asthma Management Handbook 2006 includes detailed information on spirometry. ${ }^{12}$ High quality data on the actual use of spirometry in general practice settings is not available.

Allergy testing is usually undertaken on the basis of a referral from general practice to a specialist service.

\section{Future developments}

The key challenges faced by Australia's primary health care 
sector over the next 5 to 10 years include workforce pressures, an increasing burden of chronic disease, an ageing population, multiple morbidity, and advances in technology. There are also the (as yet) unknown impacts of climate change, which in theory at least may result in increased migration from neighbouring Pacific islands with consequent increases in diseases like tuberculosis and/or alterations in the incidence patterns of vector-borne diseases.

Given these challenges, acute respiratory disease assessment and management in the primary health care sector is most likely to be affected by the workforce shortage in the short term. Changes in the epidemiology of various acute respiratory diseases as a consequence of climate change and migration patterns present longer term potential challenges.

The management of chronic respiratory diseases will require ongoing reform of primary health care services, organisation and financing. ${ }^{16}$ Reconfiguration of primary health care services will continue. Continuing expansion of roles for nurses and allied health professionals is likely, as is further refinement of Medicare to increase effective delivery of health promotion, disease prevention and chronic disease care. These kinds of directions involve substantial change from the historic orientation of the system, necessitate careful change management, and thus are likely to continue in an incremental fashion over time rather than as a radical reorientation of the system over a short space of time.

Asthma has been the focus of several policy initiatives over the last eight years. At times these have arisen from different parts of the Department of Health and Ageing, with the connections between them developed retrospectively. At a policy level, active consideration is being given to whether or not the focus on asthma should be broadened to include other respiratory diseases and the challenges presented by multiple morbidity. An overarching national primary health care policy, identifying clearly measurable outcomes across a range of conditions and aligning financial and other drivers toward achieving these outcomes, may be one means of enhancing the coherence of any future respiratory policies with other primary health care policies. The incoming Labor Government has foreshadowed the introduction of a National Primary Health Care Strategy. ${ }^{17}$ This is welcome. It has the potential to give greater policy coherence and to drive strategic reform, not only improving health outcomes in respect of respiratory health, but in primary health care conditions more broadly.

\section{Conclusion}

Australia's complex primary health care system is incrementally changing from exclusive acute- and episodiccare orientation in both the public and private sectors, to a system that delivers effective anticipatory chronic disease care as well. Acute and chronic respiratory diseases constitute a significant proportion of current general practice activity, and this is unlikely to change in the medium term. From a national policy perspective, asthma is the respiratory condition that has dominated the agenda over the last decade. This agenda may be broadened to include COPD and possibly other respiratory diseases. The incoming Labor Australian Government has stated it will develop a National Primary Health Care Strategy. This has the potential to drive strategic reform within primary health care and to realise improved health outcomes for Australians, including outcomes in respiratory health.

\section{References}

1. Australian Government, Medicare Australia. About Medicare Australia: The Australian Health System. [page on the internet] c2006 [updated 2006 June 25; cited 2006 Dec 22]. Available from http://www.medicareaustralia.gov.au/ about/about_us/aus_health_system.htm

2. The Royal Australian College of General Practitioners. What is general practice? Definition of general practice and general practitioners, 2005. Available at: www.racgp.org.au/whatisgeneralpractice

3. Australian Government, Medicare Australia. Your Health: Medicare [page on the internet] c2006 [updated 2006 Dec 15, cited 2006 Dec 22] Available from http://www.medicareaustralia.gov.au/yourhealth/our_services/am.htm

4. Australian Government, M edicare Australia. Your Health: Our services for you: about the PBS [page on the internet] c2006 [updated 2006 Dec 29, cited 2007 Jan 02] Available from http://www.medicareaustralia.gov.au/ yourhealth/our_services/apbs.htm

5. Britt H, Miller GC, Charles J, Pan Y, Valenti L, Henderson J, Bayram C, O'Halloran J, Knox S 2007. General practice activity in Australia 2005-06. General practice series no. 19. AlHW cat. no. GEP 19. Canberra: Australian Institute of Health and Welfare. http://www.aihw.gov.au/publications/gep/ gpaa05-06/gpaa05-06.pdf

6. National Aboriginal Community Controlled Health Organisation (NACCHO) http://www.naccho.org.au/M embers/About-Us.html (Accessed November 2007)

7. Australian Medical Workforce Advisory Committee. The General Practice Workforce in Australia: supply and requirements to 2013. Sydney: Australian Medical Workforce Advisory Committee; 2005 Available from http://www.health.nsw.gov.au/amwac/pdf/gp_2005.pdf

8. Asthma Cycle of Care. Australian Government Department of Health and Ageing http://www.health.gov.au/internet/wcms/publishing.nsf/content/phdasthma-cycle (Accessed November 2007)

9. Australian Government Department of Health and Ageing: National Asthma Strategy 2006-2008 http://www.health.gov.au/internet/wcms/publishing.nsf/ Content/phd-asthma-strat-06-08

10. Australian Government Department of Health and Ageing: National Chronic Disease Strategy. [page on the internet] c2006 [updated 2006 Mar 30, cited 2007 Jan 04] Available from http://www.health.gov.au/internet/wcms/ publishing.nsf/Content/pq-ncds

11. McKenzie DK, Abramson M, Crockett AJ, Glasgow N, Jenkins S, M CDonald C Wood-Baker R, Frith PA. The COPD-X Plan: Australian and New Zealand Guidelines for the management of Chronic Obstructive Pulmonary Disease 2007 http://www.copdx.org.au/guidelines/index.asp (Accessed Jan 2008)

12. Asthma Management Handbook 2006 National Asthma Council Australia http://www.nationalasthma.org.au/cms/index.php (Accessed November 2007)

13. Australian Lung Foundation Respiratory Infectious Disease Burden In Australia Edition 1, March 2007 http://www.lungnet.com.au/download pdf/ 
2007_RID_Case_Statement.pdf (Accessed November 2007)

14. Henderson J, Britt $H$, Miller G. Extent and utilisation of computerisation in Australian general practice. Med J Aust 2006;185(2):84-7.

15. Royal Australian College of General Practitioners http://www.racgp. org.au/standards/521 (Accessed Nov 2007)
16. Harris MF, Zwar NA. Care of patient with chronic disease: the challenge for general practice. Med J Aust 2007;187:104-07.

17. Official Website of the Australian Labor Party: National Primary Health Care Strategy. http://www.alp.org.au/media/1107/mshea170.php (Accessed November 2007)

Available online at http://ww w.thepcrj.org 